\title{
Email Marketing: The Most Important Advantages and Disadvantages
}

\author{
Foued Sabbagh
}

\begin{abstract}
This paper focuses primarily on the role of Email marketing and E-commerce. Email marketing is one of the most modern means and marketing methods in the world. The modern information and communication technologies also facilitate the circulation and sending of electronic messages with the highest quality and accuracy. In addition, Email marketing campaigns help to increase the sale of products in electronic shops and to target customers efficiently and legally. However, despite the benefits of Email marketing, there are also many negatives that constitute a real obstacle to promotion and marketing via this messaging system. This study focuses on discussing the most important advantages and disadvantages of Email marketing and analyzing the success factors of this marketing by avoiding these disadvantages and benefiting all these advantages.

Keywords: Email Marketing, Advantages, Disadvantages, Marketing Campaigns, Factors of Success.
\end{abstract}

\section{INTRODUCTION}

The e-mail is considered the most recent reliable means in the marketing and electronic commerce. This means represents the speediest method of exchange of digital messages on the internet. As well, it may be to book the messages received in the boxes of the receipt of the users to see when they want to. Considering that the operation of marketing by electronic mail among the best methods and the oldest and the most effective never have seen the light of day where he is emerged with the increase in the use of networks on the internet, including the sites of E-mail, the most important being Yahoo, Google Gmail. The Email marketing is increasingly recognized as an effective internet-marketing tool (Rettie R (2002)). The promotion of products by electronic mail is a better method of commercial marketing among proponents and the companies global electronic. The global reports in this field confirm that the new rich of the world are that they may operate to promote and attract customers through the means of social communication or by electronic mail. The good use of quality legal and professional manner of electronic messaging reached thousands of dollars per month for each proponent or society of marketing their products and its work on the internet.

\footnotetext{
Manuscript received on 14 May 2021 | Revised Manuscript received on 22 May 2021 | Manuscript Accepted on 15 June 2021 | Manuscript published on 30 June 2021.

* Correspondence Author

Foued Sabbagh*, Finance and Development, Faculty of Law and Economics and Politics Sciences/University of Sousse, Erriadh City, Tunisia. Email: fouedsabbagh_2010@yahoo.fr

(C) The Authors. Published by Lattice Science Publication (LSP). This is an open access article under the CC-BY-NC-ND license (http://creativecommons.org/licenses/by-nc-nd/4.0/)
}

In general, the marketing by e-mail is considered as a means of marketing excellent to attract customers and the categories targeted by their e-mail and to convince them to buy a given product according to their requests and desires. The determination of the database of customers and the addresses of their e-mails are the most important factor to choose the interested category to the domain or the product, which located promotion. As well, it may be responsible for the operation of commercial promotion of a given product to certain categories data, by the intermediary of a commission given or what is called the system of affiliation or partnership or to sell a product personally directly with a customer referred which seeks to this product. The campaigns by electronic mail is a significant marketing tool is if they are used correctly and the timely and correct category. The marketing through the electronic mail is considered among the important tools of communication on the internet, because of the many clients are in permanent contact on the applications of electronic mail either on the handheld devices such as the mobile phone or office computer automation to stay informed on the electronic messages which they received. The targeting customers and attract the largest possible number of them to participate to buy a product requires the skills and of the organization in the choice of the database which allow to achieve positive results. Each person in the world has its concerns, desires in a given area must therefore to define the objective, and the product for each person in well determined. It is understood that the email has a great popularity among the different categories of users of the internet, it should operate correctly and to avoid the methods at random and the discomfort of the receiver to these advertising messages and the promotion of products. Subsequently, it must distinguish marketing by electronic mail and by e-mail at random and disturbing. Kaur $\mathrm{R}$ and Singh G (2017), introduces a new approach concerning internet marketing in electronic commerce; showing how advertisers need this innovation to be successful. E-marketing does not consists only use to promote marketing over internet but also helps in marketing through e-mail and wireless media. Email marketing is considered the most recent of the means and methods of commercial marketing the more effective today, which aims to increase sales and to target the customers effectively and legal. Considering that, the rich of the world in this area are those who have the ability to properly target the desired groups and to promote the products of global way up to reach millions of people par day. This article would be considered a study of the advantages and disadvantages and the success factors of Email marketing.

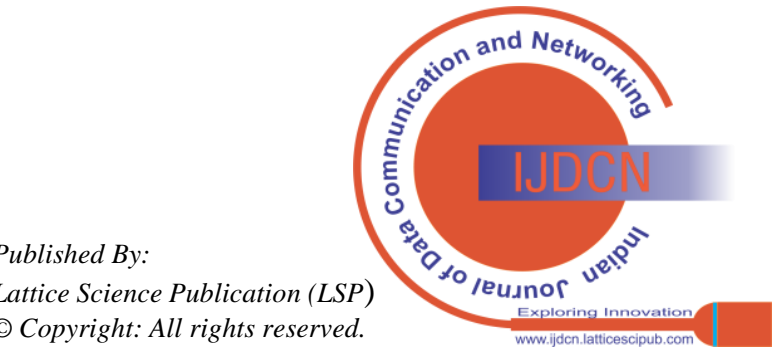


Therefore, it must therefore analyze all the steps of the operation of this type of marketing campaigns in order to save time and the increase in sales and the positive benefit of these services and to define the best terms of the practices of marketing by electronic mail. The operation to identify the most advantages of Email marketing with the basis of profit and the increase to attract customers to participate on the product prairie. On the other hand the most disadvantages of Email marketing summarizes the violation which result in the poor exploitation of Email in order to become an instrument of harassment that if he has not located the right choice. Therefore, it is necessary to adopt reliable methods for the provision of the factors of success of this marketing by electronic mail.

\section{THE MOST IMPORTANT ADVANTAGES OF EMAIL MARKETING}

The most advantages of Email marketing represent the main bases of launching campaigns of commercial marketing advertising and electronically. The most important of these advantages we note the following:

\section{A. The Ease of Use the Email Marketing}

Email marketing is a way to reach consumers directly via electronic mail (Kaur R and Singh G (2017)). Email marketing is a popular way for businesses to reach customers. Email marketing is the use of email to promote products and service. It helps develop the relationships with potential customers and clients. Email marketing is one segment of internet marketing. With the help of Email marketing, a company sends a commercial message to group of people. Is summed up in the regular methods and it is to send and receive messages, but the professional technical of marketing requires the use of modern software to conduct marketing campaigns by electronic mail. The study of Payne A and Holt S (2001) basis with review of the literature has shown the concept of value has its roots in many disciplines including psychology, social psychology, economics, management and marketing. This review also confirms how many of the concepts overlap to some degree with a blurring of distinctions across different forms of value. According to the statistics and international studies, if it has been used electronic mail by methods of professional marketing can for the proponents or the electronic society to achieve considerable profits through the increase in the sale of the products at the global level. As well, we can send a commercial message promotional or advertising to multiple recipients.

\section{B. The low Cost Compared To Other Means}

Consumers having the option of choosing an intermediate price will receive fewer calls, which will be better tailored to their interests, and will be compensated for those calls they do receive (Ayres I and Funk M (2003)). Permission marketing suggests an evolution of direct marketing, particularly used with Email (Tezinde T, Smith B and Murphy J (2002). It combines databases of customers who agree to receive marketing messages with low-cost, customized Emails that attempt to slice through advertising clutter, attract increased customer support, and change behavior. Generally the costs of sending of electronic messages for free or low costs and high quality in the delivery of information to the target customer according to their desires and their concerns. Subscriptions in the paid sites and servers to send a significant number of Emails usually at very low cost compared to the use of the means of social communication.

\section{The Customer Targeting Of Correct Way}

Phelps J.E, Lewis R, Mobilio L, Perry D and Roman N (2004) determine the results of three studies that examine consumer responses and motivations to pass along Email. Implications for target selection and message creation are discussed for advertising practitioners interested in implementing viral efforts, and suggestions for future research relating to computer-mediated consumer-to-consumer interactions are presented for academic researchers. Given the general public users of Email, can the electronic marketing to achieve a great opportunity for the promotion at a lower cost. As well, we can send a message containing a text audio or video or photos and cards. Where through the Email can determine the category and the targeted customers to sell products for them or send electronic messages have carefully. Thereafter one can divide your list of shipping (by age, specialization, the definition of the State, the geographical area, the behaviors), in order to ensure that you provide the information and the arrival your messages of commercial announcement for the targeted customers. In general, to target a particular installment you must define the content and the content of the electronic messages and redirected for customers who wish to buy this product. The qualitative research suggests that Email marketing is growing rapidly and should be integrated into the overall communication mix (Rettie R (2002)). Interviewees also believed that Email marketing would be more effective as a retention rather than as an acquisition tool, because its interactivity facilitates two-way communication. The experts interviewed also stressed the importance of targeting and the use of permission lists. As the latter varies from double opt-in company-specific lists to pooled opt-out lists, it is likely that the specificity and intensity of permission will also affect response rate. Winer R.S (2001) given the analyses, decisions about which customers to target, tools for targeting the customers and how to build relationships with the targeted customers.

\section{Check the Calendar of Management of Campaigns Of Electronic Announcements}

Online advertising, also called online marketing or internet advertising or web advertising is a form of marketing and advertising, which uses the internet to deliver promotional marketing messages to consumers (Loganathan M.S, Kumar N and Devi L (2017)). Consumers view online advertising as an unwanted distraction with few benefits and have increasingly turned to ad blocking for a variety of reasons. The launch date of the campaigns of advertisements is considered the main causes of the success of a campaign for the promotion of Email. By providing a few tools and sites of marketing by Email, a complete set of solutions for the good quality control of the timetable of cease their campaign of announcement and the proper functioning of promotion campaigns.

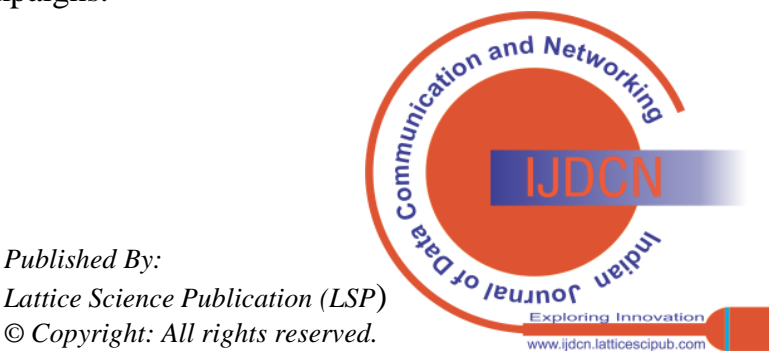


By the suite can make a temporal calendar first for each campaign to announcement for target customers sought, then to respond automatic on your messages and finally for their plan of announcement in function of the targeted public. The aim of the research of Cruz D and Fill C (2008) is to correct this deficiency and to identify the key criteria that viral marketing practitioners believe should be used to evaluate viral campaigns. This is important as commonly agreed framework of evaluative criteria can assist both campaign and cross-campaign measurement and promote increased efficiency and good practice.

\section{E. The Monitoring and Study of the Effectiveness of the Campaigns of Announcement}

Different types of modern marketing like internet marketing, Email marketing, and online advertising are all drive businesses to be successful (Salehi M, Mirzaei H, Aghaei M and Abyari M (2012). Now a day, there is no need to entering a market place to find our needs. We can find whatever we need, neither wasting time nor wasting cost, just with a quick click and use internet search engine. The study of Huang C.C, Lin T.C and Lin K.J (2009) result may well be useful to marketing practitioners who are considering Email marketing, especially to those who are in the process of selecting key Email users and or designing product advertisements to heighten the eWOM effect. Could be followed the link of the specific announcement of the by Email who have located to send customers thanks to know many people track the electronic advertisement. The Email is to provide you the success of your advertising campaign by examining the rate of success of the campaign or their effectiveness of announcement. Therefore, the study of campaigns for the announcement by electronic mail represents the level of success of the follow-up to the campaign by the target public and the participation of purchase and the error rate in the delivery of information by electronic mail and to target the installment required for the purchase of the products in marketeur.

\section{F. The Concentration on the Trademark of the Consolidation of the Campaigns and Broadcasts}

In the study of Jain Y and Garg R (2014), dynamic content and custom fields were cited as the personalization functions used most often. This was manifested in different ways, such as; better segmentation and targeting, rather than growing volume of Emails. Improving quality of customer databases, rather than growing customer lists. Personalizing Emails with behavior-driven dynamic content, rather than growing volume broadcast Emails. It is necessary to put the idea of a product whose promotion with beneficiary so that you won the customers with more effectiveness and the usefulness of the participation of purchase. The increase of the conscience by a trademark is not only that the interests of society and the increase in sales of the electronic shop specific to the, but also to a positive effect on the interests of the company outside of the transactions on the internet. It must have the several factors in the construction of the campaigns and dissemination in particular the trademarks normal for the greater part the targets and also puts the emphasis on the quality of the products by the use of logos and the name of the company and sponsor and the electronic signature special of you and disseminate the source of information.

\section{G. The Creation and the Development of Relations with Customers}

The architecture supports several personalization engines that run within the customer interaction component (Ansari S, Kohavi R, Mason I and Zheng Z (2001)). The rules defined by marketing users can be deployed for offering promotions to visitors, or displaying specific products or content to a certain type visitor. Considering that, the Email is a friend of the environment so that the marketing process does not through the paper, which helps to reduce the greenhouse effect thermal heating and therefore the process has become more sophisticated in order to obtain positive results. It's can for the user to communicate electronic messages and the length of the message in the list. The essence of the information technology revolution and, in particular, the World Wide Web is the opportunity afforded companies to choose how they interact with their customers (Winer R.S (2001)). The web allows companies to build better relationship with customers than has been previously possible in the offline world. The creation of a base and a list of addresses require a database on their target customers, account is taken of the list of their present customer in your list of messages and their well relationship with them and they should know envisaged their customer up to the provision of electronic products required. In addition, it must be their informed by the last update of your company and your product intended for the smooth development of the process of promotion and distribution. The Email marketing provided the process to establish the lists of messages, to develop, to improve the relations with the customers very quickly and of high quality with the monitoring of the results and to satisfy their desires and their needs.

\section{H. The Speed in the Management of Campaigns and Measure the Results}

In response to this growing channel of communications, marketers have begun to see that they can replicate offline advertising methods online (Chittenden $\mathrm{L}$ and Rettie $\mathrm{R}$ (2002)). Any way to communicate that is easier, cheaper or quicker always has high appeal, the internet offers all three. The timeliness in the sending of messages, where the transmission process is done in a few seconds with to inform the sender in the case of arrival or do not access the electronic messages with the follow-up of the campaign and of their results. It is also possible to measure the effectiveness of the messages of announcement. An environmental expert undertook a social marketing campaign; hereafter know as the "Advocate" (Artz N and Cooke P (2007)). Email marketing encouraged coworkers to engage in environmentally sustainable behaviors at home. As form of one-way communication, Email was used to prompt consumers to act and to portray implicitly the action as a social norm. As a form of two-way communication, Email was used to obtain commitment to act from participants. In addition, we can measure the speed of the access of advertising messages by Email and to ensure the receipt of the announcement.

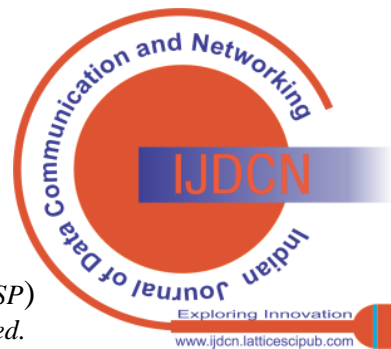


The process to send a message or the management of a dissemination campaign to a large number of Email during some time in function of the transmission program or the speed of transmission server in the process of transmission by the number of Email sent by day. The importance of Email represents as an instrument quick, efficient, and quality of the management of marketing campaigns on the internet.

The main features of electronic marketing contains an effective method to know the opinion of the targeted public with the follow-up campaigns of announcement to which the marketing of top quality. We could thus for the advertiser to allow recipients to communicate their comments and their desires and their suggestions on electronic advertisements or product prairie of him. The launch Email campaigns will require the need of computers or a mobile phone or the internet. Email marketing involves directly marketing a commercial message to a group of people using Email (Loganathan M.S, Kumar N and Devi L (2017)). In general, you can put the implementation for your campaign to announcement and to communicate with their customers in any place and at any time would like to for the management of your marketing campaign.

\section{J. The Performance and the Proliferation of Voluntary and Automatic}

Email marketing is a form of direct marketing, which uses electronic mail as a means of communicating commercial or fund-raising messages to an audience (Fariborzi $\mathrm{E}$ and Zahedifard M (2012)). It allows the possibility of the return in which mail is available by the users a great opportunity to disseminate electronic advertisements. It has canned for the user to choose the email message or the commercial operation that he wanted to on a voluntary basis or automatic, with the participation of implementation of the opinion and discuss the product, which is seized of marketing. The study of Hennig-Thuran T and Klee A (1997) involves a critical examination of the satisfaction-retention relationship, and the development of a more comprehensive view of the customer's quality perception. Customer satisfaction with a company's products or services is often seen as the key to a company's success and long-term competitiveness. A method for optimizing a marketing campaign is provided (Wardell $\mathrm{K}$ (2006)). Initially, an analysis of a client's transaction data is performed. The process to send messages automatically indefinitely and to all target customers of the main methods to promote in an effective manner and of high quality.

In general, the importance of marketing by electronic mail represented to the use governed to the methods of marketing of products on the internet in order to summarize the foregoing of the main benefits and positive of this quality in the marketing in the following points. The cost is not expensive in the method of implementation of the advertising campaigns and the announcement and to obtain new customers by day and to increase their number continues to increase the number of visitors to your site and advertising through the electronic messages, sending newsletters to adapt to the evolution of the situation, to follow the questions and the information clienteles. In function of an effective method to achieve the objectives of the corporations thanks to the speed of the arrival of electronic messages, the ease of access

\section{The Deceased of Time and of the Place of the Administration of Campaigns of Announcement}

to the evaluation of campaigns for the announcement by the use of electronic mail, the ease of communication with all clients targeted, to send advertisements of his career commercial or your service in of electronic messages, the speed of execution of the advertising campaigns, e-mail marketing does not cause any criticism, would not require the advertising expenses costly. The low cost of management of campaigns and marketing budget, the marketing of the products by received messages up to millions of persons per day and is this to create a market of global electronic commerce extended to all products, which are to promote.

\section{THE MOST IMPORTANT DISADVANTAGES OF EMAIL MARKETING}

The study of Ellis-Chadwick F and Doherty N.F (2012) examines a comprehensive range of executional elements in a sample of permission-based e-marketing campaigns. This study provides important new insights into the executional tactics used in Email marketing campaigns; it suffers from a number of limitations. In particular, it was not possible to explore the actual effectiveness of such campaigns, from either the consumer's or the retailer's perspective. In addition, Bucklin R.E and Sismeiro C (2009) discuss the nature of click stream data, noting key strengths and limitations of these data for research in marketing. Despite the high quality of service provided by the electronic mail to the proponents and the electronic companies, but that the improper use of this method will certainly of obstruction and the failure of commercial marketing. In addition, the defects of marketing by Email represent the most important disadvantages of this type of marketing. Therefore, we can summarize these disadvantages in the following points:

- Some people beneficiaries located in this quality of marketing messages by electronic mail are messages at random, which leads to a lack of interest and the delete.

- The use of excessive and non-legal the database of addresses clienteles.

- The operations of conversion and promote imaginary of the products not present on world markets.

- The presence of fictitious companies claims ownership of a product well known and of high quality and this for deceit and rhythm of the user for the work illusory and the ex gratia payment.

- The deletion of messages without disturbing the consult.

- The operations of announcement and advertising not organized and who have sent to persons are not interested in this product.

- The campaigns targets have negatives results.

- The presence of many of the conservators who sell the illusory on internet networks it must therefore the right choice before making the promotion of a certain product.

- The operations of deception and pace of proponents and clients in the illusion without payment of a commission of work or service.

Obtaining a reasonable level of response from Email surveys and direct marketing via Email is usually seen as notoriously difficult (Brandal H and Kent R (2003)).

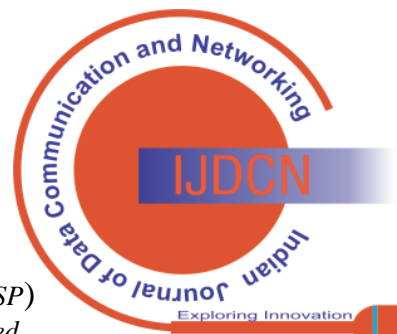


In general and in accordance with the laws in force in the world there is in the developed countries a security organ global electronic wishes of the legality of work on the networks of the internet and the follow-up of all of the excess. Each criminal attack against another person or a company and if it is published a complaint in his official law can he followed in some countries of the world. For example, if the victim of the United States and the aggressor of Africa the body of electronic security capable of attracting the accused to the American justice. Some companies are anxious to make procedures such as to compel the user to enter a mail already exists in the kind of check of the property and to include messages by link to remove the subscription or disable the site that deals with him. As well in the form if there is any legal exceeded it located the total cancellation of the subscription and the site completely on the networks of the internet, and that even to save legal prosecution for the evidence to interfere with the people through the electronic mail at random, and to emphasize the movements which have to preserve the rights of the user, the movement CAN-SPAM Act of American in 2003, and which requires marketeur a legal others of a fine of approximately 11000 dollars for each user violate its priority. In addition, the system security organs of the global electronic, which protect the legal status of the publicity, work products and trademarks in the world and the operations of promotion and electronic marketing. The fact that these monitoring bodies of any person in the world if appeared in his right of any complaint international.

\section{THE FACTORS OF SUCCESS OF E-MAIL MARKETING}

The study of (Dheeraj N and Pars J (2017); Kaur R and Singh G (2017)) discussed about the top motivator factors of shopping online. Being of the main success factors of e-mail marketing is the additive information by their clients to the list of subscribers, which allows you to remain in permanent connection and on a regular basis with them by the directorate of marketing and promotional campaigns. Subsequently the main factors to launch campaigns by electronic mail are summaries of the following measures (Fig.1):

\section{A. The First Step: Access to Programs E-Mail Marketing}

The first step in the beginning is started by engage and downloads marketing programs by electronic mail. Therefore, these programs provide the basis of the addition of the data by your target customers and the one by the collection of Email addresses and other details about your visitors to the site to exchange something you present free of charge or by a compensation paid. It also exists in the internet network of much software contributing to the good development of the management of marketing and promotional campaigns by Email so that you choose between them, which are compatible with your budget. The use of special programs by the Email allows you to establish the list of titles of electronic messages many target customers and then the development and programming of a series of these automated messages and which is known under the name of automatic response or Email unique, and are generally for the management of advertising campaigns for marketing. It is also possible thanks to these software follow the statistics and to know the number of persons who have opened and read your electronic messages and the interaction together by the subscription or the purchase of the products the prairies. In general, it is necessary that the programs used in the campaigns by Email is revealed on the fundamental bases of the promotion and organized transmission to customers, so that the content of message sent to the requirements of the person. Subsequently it must take into account the good collection and organization the subscriptions in your lists of messages. As well, it must also on the commitment of equal periods in the process of the sending to clients in order to ensure that the work be more specific and target in time and the person required. The acquisition of ad hoc programs, adopted by global corporations of electronic messaging establishes a timetable for all the operations of the sending by Email. Where, the correct use and legal framework of these programs contributed to the success of marketing campaigns and advertising and the increase of electronic sales.

\section{B. The Second Step: The Free Presentation of an Offer None Resists}

The free offer represents to give visitors to your site an attractive character cannot be abandoned to the reading of the announcement and the entry into promotional page specific to your own. Given that this free offer and to take multiple forms is an example as a report in PDF format, electronic small books can download, audio discs, advertisements, electronic sessions, videos and addendum of the visits. By following, this offer makes it easier to attract targeted clients to the admission and registration, and to add a large number of visitors by e-mail. When a person allows registering on the site of the free offer, it becomes a customer interested in one of the ideas and objects that have been developed for the free offer. As well, it contributes this process to organize the operations to send targeted to the list of electronic messages and to remain in permanent contact with the list of registered customers. In addition, to be able to the processes of the sending of the e-mail messages specified in the organization of the process to provide participants with information and useful products in accordance with their wishes and their interests and to follow the evolution of the market. In general, these advertising campaigns by Email help to the building of confidence and credibility between the two parties. This information leads to attract their attention and to obtain a free registration. We can summarize the results of this free offer in the many benefits including the time and the increase in sales, to facilitate the process of the establishment of the lists for customers and send newsletters and advertisements as soon their pressure on the button, the possibility to measure the results of promotion of products through e-mail campaigns, to find quick solutions adapt to the marketing operations by electronic mail and to establish the lists of messages. This step provided to put a free offer irresistible additional benefit of marketing campaigns by electronic mail based on a legal authorization. The lists of the campaigns by Email marketing represent mainly the creation of the database and the addresses for the quality of the customers can receive your advertising messages and promotion.

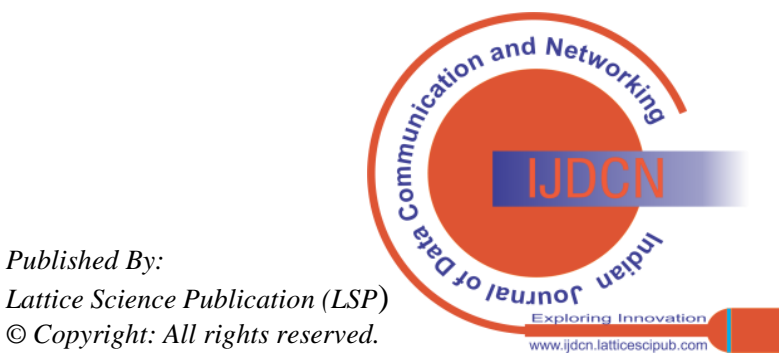




\section{The Third Step: The Development of a Series of Automatic Replies for the Electronic Messages}

We can exploit the campaigns by electronic mail by of automated methods and it is here means of advertising marketing sender in an automatic way consecutive. The process of electronic mail is immediately and automatically in common given to a subscriber to receive your messages and your promotion offering. This process includes a series of Email messages that automated will surrender to the wire of time for a slice of the targeted individuals. The first reaction allows you to do a definition of your personality and to present your work and to allow for your public to identify the different types of information circulating, when you made the promotion and that can be achieved and the number of times to send your electronic messages. It will contain this service of the connection for your free offer or a full explanation for the subscriber on the way to registration or the access to the offer that bring. In this context, it should concentrate on the side of the target of automatic communication marketing with clienteles and the use of legal programs to transform the sending of the messages of automatic way and in a precise timetable. It is necessary to avoid the sending at random disturbing people who do not you know or unknown and which may cause to you problems if the person is not interested in this kind of Email. On the other hand, the sending of electronic mail II, III and IV of two or three days after it must contains a useful set of information or products prairies of him or the other useful services available on the networks of the internet. Any over run of the use of electronic messages can be submitted to its owner of sanctions including, the automatic closure for your site messages or cancel your subscription to the service of registered mail of him or issued in research, if it appeared from the a complaint of inconvenience and breach for the personal data which will cost you pay a financial penalty or to appear before the justice, if the applicant follow you accused of inconvenience repeated. The automatic reply allows you to bursar of the considerable time, but it must be good use by legal methods and to the persons involved in this area or of this service. In general, the process of creation of this type of messages once and then forgot to make the programs of the operation of the automatic sending is considered easy and does not require significant costs. This type represents a considerable risk if it became a source of interfere for the recipient in order that it must concentrate on the target category to avoid the concern of the clienteles of this quality of electronic messages. The other successive messages after the first automatic response are very important to win the confidence of your target audience in the promotion process. Subsequently, it must be become the content of a high value for the clientele's subscribers to receive your electronic messages.

\section{The Fourth Step: The Methods to Create a Continuous Plan for E-Mail Marketing}

The importance of the creation of a continuous plan Email marketing represents in the construction of relations based on mutual trust with all the members of the specific list of the. This process through the mechanisms in the programs that govern the operation of the marketing and promotional campaigns by Email, though the organization of the sending and to choose the content that conforms to the wishes of the target customers with the addition of the images of the products and for electronic payment services or the services of registration. It is considered this marketing method among the best types of marketing which depends to attract the greatest number of visitors intended to participate in the purchase of the products the prairies of their and it by advertisements through special newsletters of the or by e-Zine (electronic newspapers) or advertising sales and marketing. The fundamental objective of this quality of marketing by Email is to always remain in permanent contact and face with targeted clients repeatedly. Where, it is of service a commercial developer products and services of reminder of their clients on a regular basis of the variables in the global market electronic and recalling of them of your offers and your experiences. In addition, research and innovation in the methods and mechanisms for the promotion and targeting clienteles according that they want. Among, the important of these methods of success of your campaigns by Email is to define the objectives and establish an integrated plan and global containing the important elements, such as the mapping and the quality of the contents and the sending regular, the type of information or themes that are sent, the access to your customers in a timely manner with accurate information. It should be before the beginning of any campaign by Email of capture of contact information, the construction of a data base for the electronic addresses targeted with the determination of the construction of a database for the electronic addresses targeted with the determination of the customers who wish to the services that your provided, communicate regularly by your customers and provide an additional value through quality services particularly specific to you. Finally, after the exploitation of the database and the choice of software that organize the work of Email it must avoid the mail of propaganda of others that is not desirable, because it is at random and disturbing and cause you problems either to close your account of the message completely by the intermediary of a supplier of internet services or pay a fine for the victim or for the judicial follow-up for repeated harassment, if have caused a large considerable harm to the user at the level of their Email. The best method to ensure the promotion and marketing of commercial products by Email for the products through the direct mail and authorized him, and that by the purchase of a base of data by the address of the target customers or the good choice of persons subscribers to the service of your commercial marketing. Subsequently may not be a concern regarding the process of promotion because all receive acceptable to the reception of this quality of ISP communications of the source of a supplier of internet services, in order to lead the management of campaigns in legal terms and conditions and with positive results.

\section{CONCLUSION}

The findings of the study Fariborzi $\mathrm{E}$ and Zahedifard $\mathrm{M}$ (2012) offer some advantages and disadvantages of using Email marketing and showed how it can be decreased its disadvantages by using some improving techniques. The commercial marketing and promotional materials to electronic products by Email is considered the new method of organization of campaigns in order to attract the largest possible number of customers earn a commission or direct benefits.

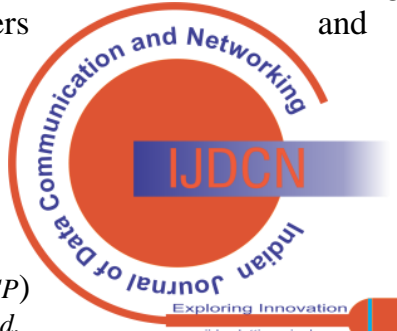


Where as it has been published in the global reports which are interested in this area emphasizes that this type of promotion allows to realize the financial benefits significant because it represents an important global market containing millions customers by day. Subsequently, in this part of the work by the internet it must oversee the marketing professional commercial electronic products according to scientific methods of professional character and experience. The use of the mechanisms of professional promotion requires the use of the software of the top quality of the management of the campaigns. An Email campaign was developed using the social marketing tools of commitment, prompting, and social norms (Artz N and Cooke P (2007)). The research of Brandal H and Kent R (2003) shows that many permission based Emails are not read and are not found to be interesting, illustrating that there is room for improvement. The marketers should get to know their customers preferences better, and develop a mutual relationship where by customers are encouraged to respond. It must determine the key benefits and positive marketing by e-mail including the ease of the use of Email and to send and receive electronic messages. As regards the costs, this type of commercial marketing are considered low compared to the other means, such as the means of social communication. With regard to the side of the target of the clients, require concentration on a given category in a given place for the purchase of a given product according to their desires. We must control the time limits for the management of campaigns of electronic products prairies, in focusing on the trademark in the construction of the campaigns and the publication for the target customers with the authorization of the quality of the products subject to promote for the recipient of this type of electronic messages. The creation and the development of relations with customers, speed in the management of campaigns and measure results, provide the time and the place of the management of campaigns of announcement with the adoption of the performance and voluntary proliferation and automatic are considered from the most important benefits of commercial marketing through the Email in order to attract the largest possible number of customers to participate in the purchase of a given product by internet. Subsequently, it is available of these conditions in the process of promoting a more professional manner and with positive results in the developed countries including the United States and the European Union and the countries of the Gulf where the rate of participation for the purchase of electronic products more high compared to some other countries. Therefore, you can have made huge profits through a commission or a total profit by the sale of electronic products but in poor countries, you cannot be assured that what you want of sales since the majority of the people deplore the lack of material means and the use of modern techniques. In general, the American market and European level and of the Gulf are considered the best global markets which has a digital economy developed and modern technologies available in the factors of success and make profits but the under-developed countries continue to ignore this type of world trade, so that it judge of nature of scam and fraud and here there is a lack of confidence due to the environment ignorant and poor who may not promote as this type of electronic products. The most important disadvantages of this type of Email marketing, we note the campaigns of Email disturbing and at the random, the use of excessive and not legal the database of addresses of customers, the operations of conversion and the sites of the shell companies who do not pay to the proponents of the commissions, the irregularity in the sending of electronic messages and deception the proponents and clients in the illusory. Where among the important factors of success of Email marketing is to adopt the following measures, which is summarized as follows the first step is to obtain marketing programs by Email which are represented by the methods of management of marketing and promotional campaigns legal, the second step is to put in place a free offer irresistible in order to attract the largest number of visitors to your site and special target customers who are desired, the third step consists of a series of automatic responses of electronic messages and the adoption the automation of send electronic messages in software universal in a legal nature used by large global companies electronic. The fourth step is considered the most important in the methods of the creation of a continuous plan marketing by direct mail and authorized to him and to avoid methods at random who are caused to the proponent of the legal problems, where it can be the penalty for the misuse and operating to fully close your electronic account staff by the distributor of the internet and to pay a financial penalty for the victim or for the judicial follow-up for the repeated harassment. The Email marketing considered lawful and targeted persons wishing to receive this type of Email and by result, they participate automatically according to their desires to provide products for them according to their interests. By following, this type of promotion allows to realize the financial benefits considerable and refer to rich archaeological of the world if it was used in a legitimate manner and legal and to avoid the sites of the fraud and the use of methods protectionists of promotion.

\section{REFERENCES}

1. S. Ansari, R. Kohavi, L. Mason, and Z. Zheng, (2001), « Integrating E-commerce and Data mining: Architecture and challenges », IEEE, pp.27-34. [CrossRef]

2. N. Artz, and P. Cooke, (2007), « Using E-Mail Listservs to Promote Environmentally Substainable Behaviors », Journal of Marketing Communications, Vol.13, n 4 , pp.257-276. [CrossRef]

I. Ayres, and M. Funk, (2003), « Marketing Privacy: A Solution for the Blight of Telemarketing (and Spam and Junk Mail) », Yale Journal on Regulation, Vol.20, n77, pp.78-137. [CrossRef]

3. R.E. Bucklin, and C. Sismeiro, (2009), «Click Here for Internet Insight: Advances in Clickstream Data Analysis in Marketing », Journal of Interactive Marketing, Vol.23, pp.35-48. [CrossRef]

4. H. Brandal, and R. Kent, (2003), « Improving email response in a permission marketing context ", International Journal of Market Research, Vol.45, n4, pp.1-13. [CrossRef]

5. L. Chittenden, and R. Rettie, (2003), « An evaluation of e-mail marketing and factors affecting response », Journal of Targeting, Measurement and Analysis for Marketing, Vol.11, n³, pp.203-217. [CrossRef]

6. D. Cruz, and C. Fill, (2008), « Evaluating viral marketing: isolating the key criteria », Marketing Intelligence \& Planning, Vol.26, Issue.7, pp.743-758. [CrossRef]

7. N. Dheeraj, and J. Paras, (2017), « E-Commerce and Insurance Internet Marketing: A Business Review from Indian Context », International Journal of Scientific Research and Management, Vol.5, Issue.09, pp.7124-7128.

8. F. Ellis-Chadwick, and N.F. Doherty, (2012), « Web advertising: The role of e-mail marketing », Journal of Business Research, Vol.65, pp.843-848. [CrossRef]

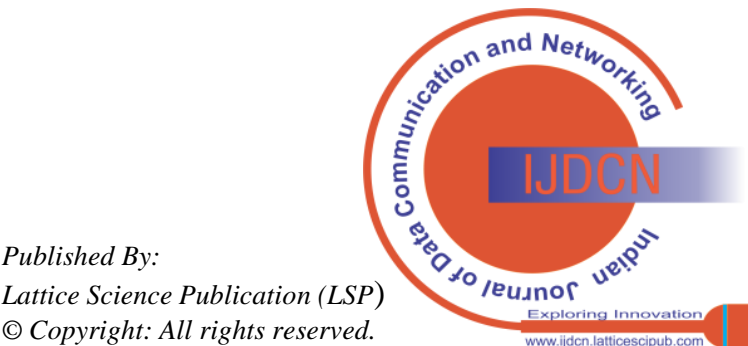


9. E. Fariborzi, and M. Zahedifard, (2012), «E-mail Marketing: Advantages, Disadvantages and Improving Techniques », International Journal of e-Education, e-Business, e-Management and e-Learning, Vol.2, $\mathrm{n}^{\circ}$ 3, pp.232-236. [CrossRef]

10. T. Hennig-Thurau, and A. Klee, (1997), « The impact of customer satisfaction relationship quality on customer retention: A critical reassessment and model development ", Psychology \& Marketing, Vol.14, n8, pp.737-764. [CrossRef]

11. C.C. Huang, T.C. Liu, and K.J, Lin. (2009), « Factors afeecting pass-along email intentions (PAEIs) : Integration the social capital and social cognition theories ", Electronic Commerce Research and Applications, Vol.8, pp.160-169. [CrossRef]

12. Y. Jain, and R. Garg, (2014), « Business Intelligence: National email benchmarking report 2013 », Journal of Direct, Data and Digital Marketing Practice, Vol.16, n², pp.92-97. [CrossRef]

13. R. Kaur, and G. Singh, (2017), « Internet Marketing: The New Era of Innovation in E-commerce ", International Journal of Scientific Research in Computer Science, Engineering and Information Technology, Vol.2, Issue.1 pp.253-258.

14. M.S. Loganathan, N. Kumar, and L. Devi, (2017), « Effects of online advertising on consumers in Coimbatore city », International Education \& Research Journal, Vol.3, Issue.09, pp.52-54.

15. Payne, and S. Holt, (2001), «Diagnosing Customer Value: Integrating the value process and relationship marketing ", British Journal of Management, Vol.12, pp.159-182. [CrossRef]

16. J.E. Phelps, R. Lewis, L. Mobilio, D. Perry, and N. Raman, (2004), «Viral Marketing or Electronic Word of Mouth Advertising: Examining Consumer responses and motivations to passa long email ", Journal of Advertising Research, Vol.44, Issue.4, pp.333-348. [CrossRef]

17. R. Rettie, (2002), "Email Marketing: Success Factors », Working paper, Kingtom Business School.

18. F. Sabbagh, (2017), «Email marketing campaigns », Edition Knoowy, Study Documents.

19. M. Salehi, H. Mirzaei, M. Aghaei, and M. Abyari, (2012), «Dissimilarity E-marketing VS traditional marketing », International Journal of Academic Research in Business and Social Sciences, Vol.2, ${ }^{\circ} 1$, pp.384-389.

20. T. Tezinde, B. Smith, and J. Murphy, (2002), « Getting Permission: Exploring Factors Affecting Permission Marketing », Journal of Interactive Marketing, Vol.16, nº, pp.28-36. [CrossRef]

21. K. Wardell, (2006), "Method for Optimizing a Marketing Campaign », Patent Application Publication, Sheet.1-13.

22. R.S. Winer, (2001), «Framework for customer relationship management », California Management Review, Vol.43, n4, pp.89-105. [CrossRef]

\section{AUTHORS PROFILE}

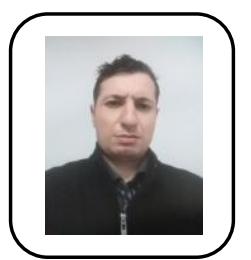

Foued Sabbagh, Masters Degree in economics sciences specialty Finance and Development in 2010 from the Faculty of Law and Economics and Political Sciences of Sousse - University of Sousse Tunisia and International Economic Researcher, fouedsabbagh_2010@yahoo.fr https://www.academia.edu/FouedSabbagh

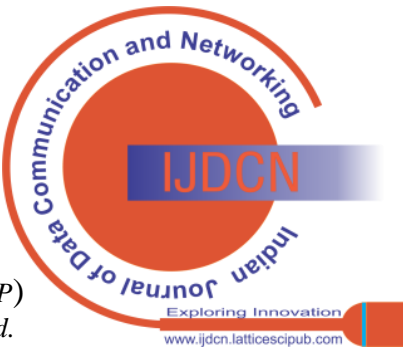




\section{ANNEXES}

Fig.1. The Email marketing campaigns strategies
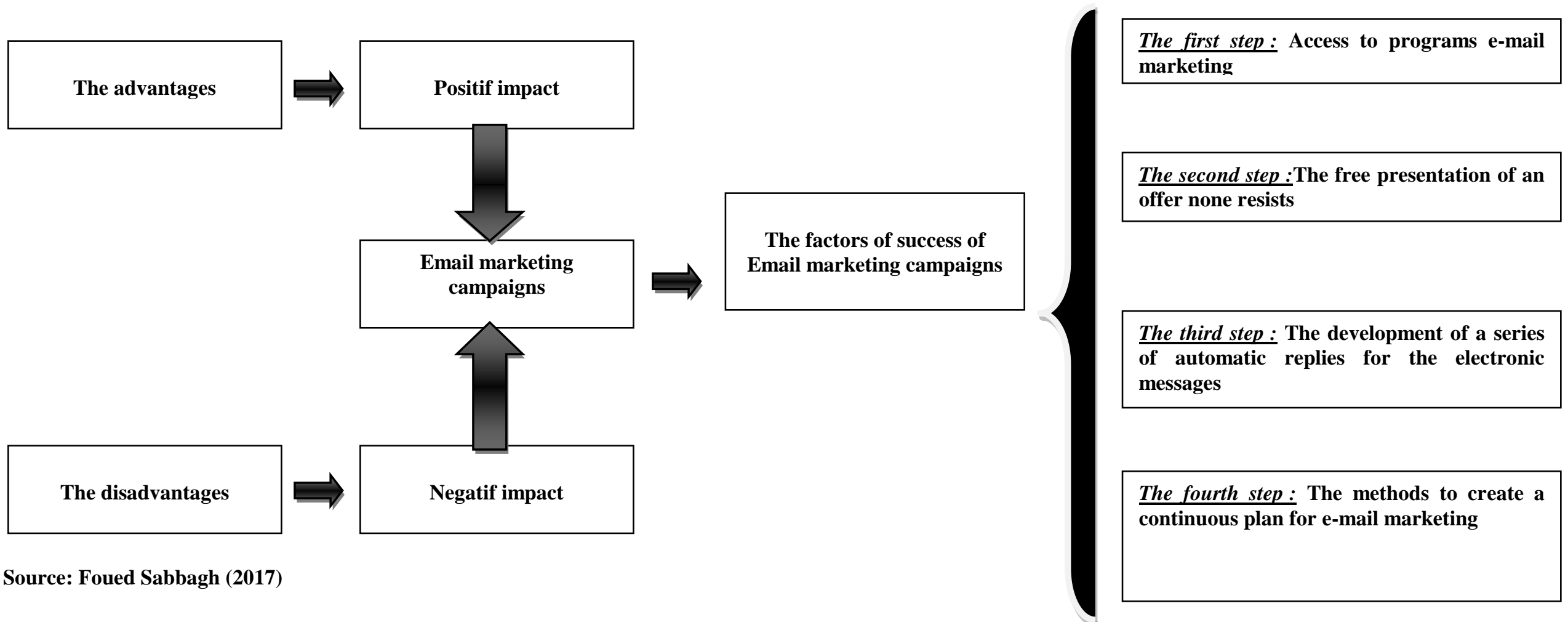

Source: Foued Sabbagh (2017)

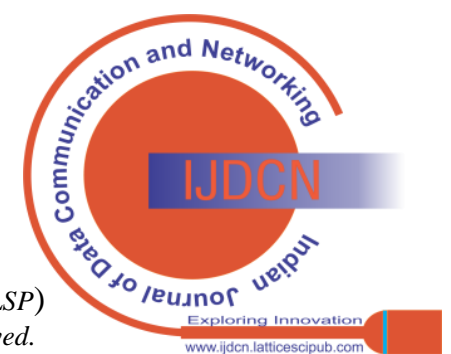

